Atle Mysterud • F. Javier Pérez-Barbería

Iain J. Gordon

\title{
The effect of season, sex and feeding style on home range area versus body mass scaling in temperate ruminants
}

Published online: 17 May 2001

(C) Springer-Verlag 2001

\section{Oecologia (2001) 127(1):30-39}

The first three sentences of the Introduction should read:

Considerable effort has been made to determine how the home range area (HR) of mammals scales with body mass $(M)$ for a wide range of taxonomic groups $\left(\mathrm{HR}=\mathrm{aM}^{b}\right.$; McNab 1963; Harestad and Bunnell 1979;
Damuth 1981; Mace and Harvey 1983; Lindstedt et al. 1986; Swihart 1986; Swihart et al. 1988; Gompper and Gittleman 1991). For energetic demands the scaling coefficient $(b)$ is expected to be 0.75 (McNab 1963). However, most studies have recorded a slope steeper than this $(1<b<1.4$; e.g. Harestad and Bunnell 1979; Mace and Harvey 1983; Lindstedt et al. 1986).

The online version of the original article can be found at http:// dx.doi.org/10.1007/s004420000562

\author{
A. Mysterud ( \\ Department of Biology, Division of Zoology, University of Oslo, \\ P.O. Box 1050 Blindern, 0316 Oslo, Norway \\ e-mail: atle.mysterud@bio.uio.no \\ Tel.: +47-22-854045, Fax: +47-22-854605 \\ F.J. Pérez-Barbería · I.J. Gordon \\ The Macaulay Land Use Research Institute, Craigiebuckler, \\ Aberdeen, AB15 8QH, Scotland, UK \\ F.J. Pérez-Barbería \\ Instituto de Recursos Naturales y Ordenación del Territorio, \\ 13 Independencia, Oviedo, 33071, Spain
}

